\title{
Substrate Integrated Waveguide Cavity Filters: Miniaturization and New Materials for IoT Applications
}

\author{
Cristiano TOMASSONI ${ }^{1}$, Maurizio BOZZI ${ }^{2}$ \\ ${ }^{1}$ Department of Engineering, University of Perugia, Perugia, Italy \\ ${ }^{2}$ Department of Electrical, Computer and Biomedical Engineering, University of Pavia, Pavia, Italy \\ cristiano.tomassoni@unipg.it, maurizio.bozzi@unipv.it \\ Submitted July 31, 2017 / Accepted July 31, 2017
}

\begin{abstract}
This paper presents an overview of the current research trends in the field of substrate integrated waveguide (SIW) technology, with particular emphasis on the issues related to the emerging applications in the framework of the Internet of Things (IoT) and the fifth generation of mobile communication (5G). More specifically, different techniques adopted to miniaturize SIW cavities are described, with the aim of reducing the footprint of SIW components and filters. Moreover, the use of innovative materials, like paper, textile and $3 D$ printed dielectric substrates, is presented and discussed, and the implementation of ecofriendly, wearable, and fully $3 D$ structures is illustrated.
\end{abstract}

\section{Keywords}

Substrate integrated waveguide (SIW), filters, paperbased electronics, wearable microwave components, additive manufacturing

\section{Introduction}

The rapid evolution of new applications in the framework of the Internet of Things (IoT) [1], [3] and the fifth generation of mobile communication (5G) [4], [5] poses a set of requirements for the developers of microwave wireless systems. Besides the low cost, the fast design process, and the simple fabrication technology, the future generation of microwave systems needs to exhibit easy integration, compact size, as well as the possibility to be implemented on unconventional materials (like paper, textile, and 3D printed materials).

The future generation of microwave systems needs to integrate in a single device the microwave circuitry, sensing capability, and wireless transmission of data and (possibly) power. In order to keep the design and fabrication costs as low as required by the market, the use of a single, suitable technology is mandatory.

Moreover, specific applications require the use of innovative materials that are not commonly used in the fabri- cation of microwave circuits: wearable components and antennas, for instance, can be conveniently integrated on garments, by adopting the textile as the substrate material. Ecofriendly applications, in the field of agriculture and environmental monitoring, can benefit from the use of paper (instead of plastic) for the dielectric substrate.

In this scenario, the substrate integrated waveguide (SIW) technology [6], [7] represents a particularly suitable candidate, due to its capability to implement passive components, active devices, and antennas by using a single technology and manufacturing process. High performance components in terms of losses are usually realized by using waveguide technology. A lot of effort has been devoted to mass and weight reduction for this technology [8]-[11], even in combination with high dielectric materials [12], [13]. The main problems remain their integrability. SIW is the integrated version of this technology and is very competitive from the point of view of losses. In fact, the SIW technology allows to implement interconnects and cavities by using a standard printed-circuit board (PCB) process, based on a laminated dielectric substrate and metal vias that provide the lateral confinement. SIW technology presents several advantages over other planar technologies (e.g., microstrip line and coplanar waveguide), such as complete shielding, and low loss, while preserving a low fabrication cost and a well-established manufacturing process.

One of the major limitations of SIW structures, however, is related to the dimensions, which depend on the operation frequency and the dielectric material. While using dielectric substrates with high permittivity allows reducing interconnect and cavity size, it has typically a detrimental effect on losses, and consequently it leads to poor quality factors. For this reason, several solutions have been proposed to reduce the size of SIW structures, including the substrate integrated folded waveguide [8] and the half-mode substrate integrated waveguide [15].

This paper presents an overview of recent achievements in the implementation of novel SIW cavity filters for IoT applications, with particular emphasis on the miniaturization and the use of new materials. The use of folded, half-mode and quarter-mode SIW cavities will be discussed 


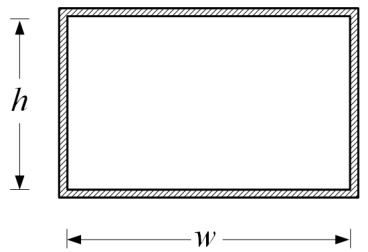

(a)

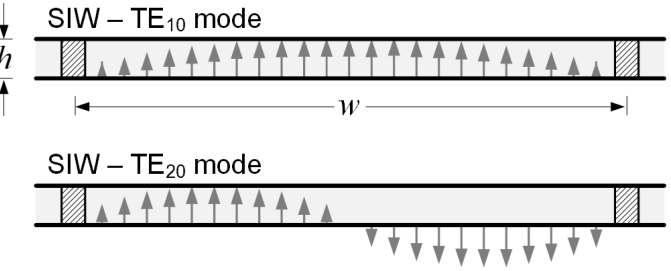

(b)

Fig. 1. Geometry comparison of a standard and an integrated waveguide: (a) Cross section of a standard rectangular waveguide; (b) Cross section of a substrate integrated waveguides, and electric field of the first two modes.

and several filters based on these structures will be presented. Moreover, the implementation of SIW filters on paper (for eco-friendly applications), on textile (for wearable systems), and by $3 \mathrm{D}$ printing (to exploit the maximum versatility and to tailor the material properties) will be presented and discussed through several examples.

\section{Miniaturized SIW Cavities}

The substrate integrated waveguide represents an integrated version of the classical rectangular waveguide [6], [7]. As shown in Fig. 1, the main difference in terms of dimensions resides in the height: in the standard rectangular waveguide the height $h$ is usually about a half of the width $w$, while in SIW the dimension $h$ is much smaller than $w$ and it corresponds to the thickness of the dielectric substrate, used in the PBC fabrication.

\subsection{Folded SIW Cavity}

The basic idea of folded SIW is to reduce the footprint by folding the structure around a metal septum [8]. This solution allows reducing the footprint of the structure by a factor two.

A folded SIW can be obtained by using a two-layer topology (Fig. 2). The metal septum between the two layers is connected to the side posts on one side, whereas it leaves a gap on the opposite side. This leads to a U-shaped waveguide. The electric field of the fundamental mode of the folded SIW is depicted in Fig. 2 (above) and in practice corresponds to the fundamental $\mathrm{TE}_{10}$ mode of the standard rectangular waveguide, once the waveguide is folded around the metal septum. Conversely, the electric field of the second mode of the folded SIW is illustrated in Fig. 2 (below): this mode corresponds to the $\mathrm{TE}_{20}$ mode of the standard rectangular waveguide, after folding the structure around the metal septum.

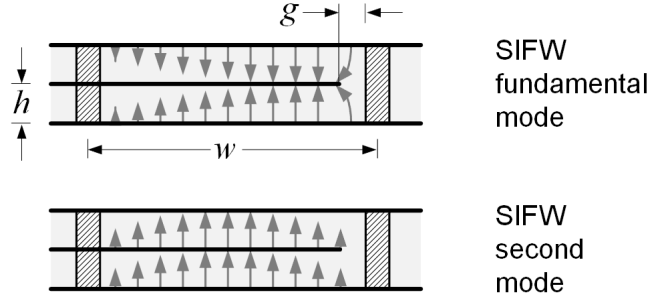

Fig. 2. Geometry of a folded SIW and representation of the electric field of the first two modes.

Note that the fundamental mode exhibits an odd symmetry with respect to the middle plane between the two dielectric layers, while the second mode shows an even symmetry.

Because of its topology, this structure can be easily fed by stripline and, thanks to the modal symmetry, the stripline excites the fundamental mode but not the second $\left(\mathrm{TE}_{20}\right)$ mode, thus resulting in a wider spurious free behavior.

The gap $g$ between the metal septum and the side posts (Fig. 2) affects the resonance of the folded waveguide by changing the electrical length of the structure. In particular, the narrower the metal septum, the higher is the waveguide cutoff frequency. This effect can be exploited for obtaining filtering structures as that sketched in Fig. 3 [16]. In this case, the waveguide sections with a large septum alternate to waveguide sections with a narrow septum (which defines the insets). Large-septum waveguide sections behave as resonators, narrow-septum waveguide sections behave instead as impedance inverters. This leads to the classical equivalent circuit shown in Fig. 4, consisting in transmission lines and admittance inverters.

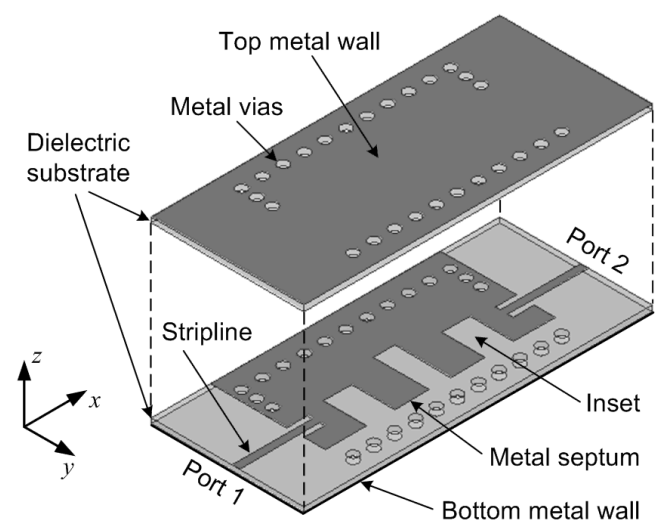

Fig. 3. Geometry of a filter based on the folded SIW cavity (from [16]).

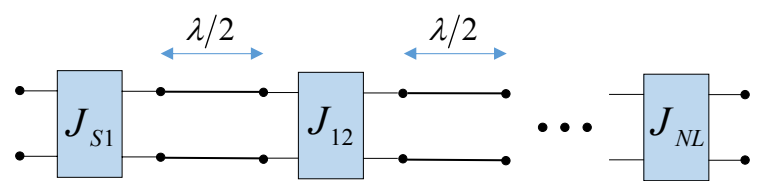

Fig. 4. Equivalent circuit of folded SIW filter. 
By using the proposed topology, a two-pole filter centered at $4.5 \mathrm{GHz}$ with $1.4 \mathrm{GHz}$ bandwidth has been designed and manufactured [16]. The filter design can be performed in two different ways: the classical way is based on the properly dimensioning of resonator lengths and insets, to realize the filtering response of the equivalent circuit in Fig. 4. The second technique, described in [16], is based on the tuning of the resonant modes of the cavity, by modifying the size of the insets.

The filter has been manufactured by milling technique, by adopting two layers of Taconic TLX-9 laminate, with dielectric permittivity $\varepsilon_{\mathrm{r}}=2.5$, loss tangent $\tan \delta=0.0019$, and thickness $h=0.76 \mathrm{~mm}$. The photograph of the prototype is shown in Fig. 5a. The comparison between measured and simulated scattering parameters is reported in Fig. 5b.

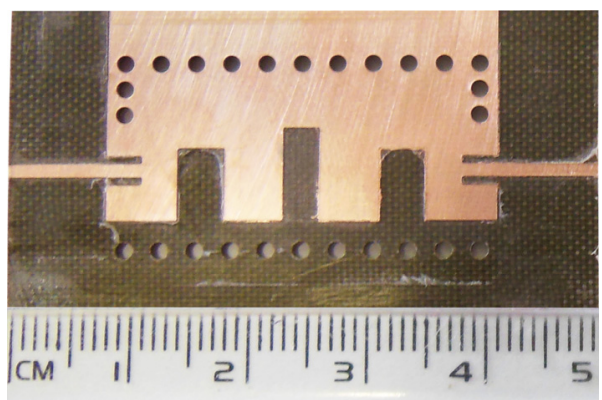

(a)

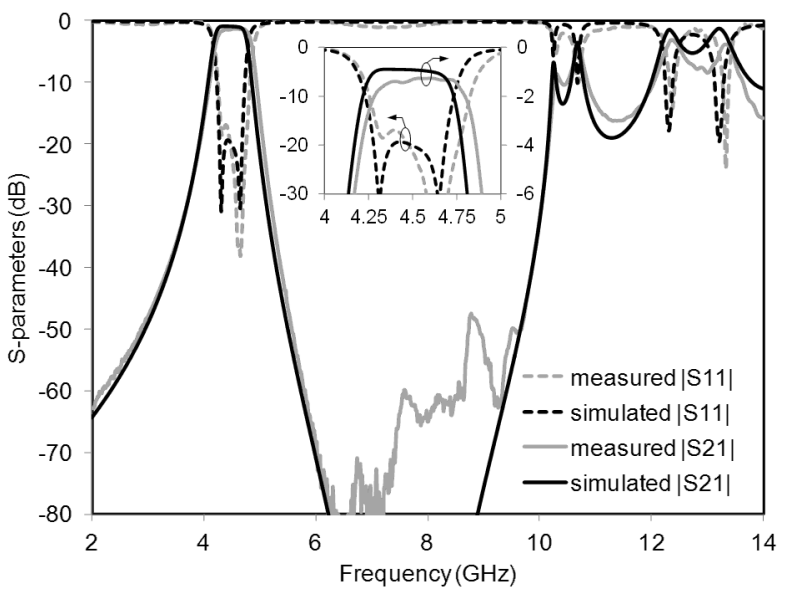

(b)

Fig. 5. Second order filter based on a dual-mode folded SIW cavity (from [16]): (a) Photograph of the bottom layer; (b) Comparison between simulated and measured scattering parameters of the filter.

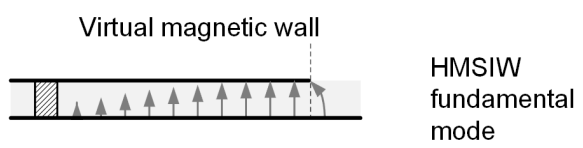

Fig. 6. Geometry of a half-mode SIW and representation of the electric field of the fundamental mode.

\subsection{Half-Mode SIW Cavity}

As shown in Fig. 1b, the fundamental mode of the SIW structures exhibits a magnetic wall in the vertical symmetry plane. This suggests that it is possible to use just a half of the SIW if the cut is closed with a magnetic wall.

Unfortunately, on the contrary of the electric wall that can be created simply by a metallic material, the magnetic wall is more difficult to realize. The behavior of the magnetic wall can be approximated by exploiting a high impedance load. According to Fig. 6, an abrupt interruption of the upper SIW wall results in a high impedance discontinuity. This effect can be considered a sort of virtual magnetic wall, and this allows to obtain the half-mode substrate integrated waveguide (HMSIW) [15].

The same concept can be exploited in the design of cavity resonators, to be adopted in the implementation of filters. Of course, the fact that the impedance is high but not infinite leads to an electromagnetic field that is not completely confined inside the SIW. Therefore, a small leakage due to radiation is present. This effect decreases the Q-factor. In any case, lower SIW height $h$ or higher dielectric constant allow the implementation of a better virtual magnetic wall (with a higher Q-factor).

By using the HMSIW technology, it is possible to realize a filter with a geometry very similar to that used for folded waveguide, as firstly proposed in [17]. In fact, the fundamental mode of the HMSIW can be excited by a microstrip line, same as the fundamental mode of the folded SIW can be excited by a stripline. According to Fig. 7, wide HMSIW sections can be exploited as resonators, while narrower sections can be used to implement admittance inverters. This leads to the implementation of the circuit of Fig. 4, where narrower HMSIW sections correspond to lower values of impedance inverters.

By adopting the proposed geometry, a four-pole filter with central frequency at $4.5 \mathrm{GHZ}$ and $1.4 \mathrm{GHz}$ bandwidth has been designed and manufactured in [17]. In this case, the fabrication required the processing of one single layer of Taconic TLX-9 laminate, with a complexity reduction compared to the folded SIW filter proposed in the previous section. The photograph of the prototype is shown in Fig. 8a, and the comparison between measured and simulated scattering parameters is reported in Fig. $8 \mathrm{~b}$.

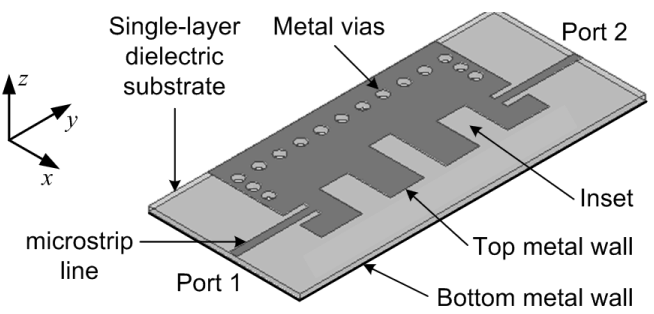

Fig. 7. Geometry of a filter based on the half-mode SIW cavity (from [17]). 


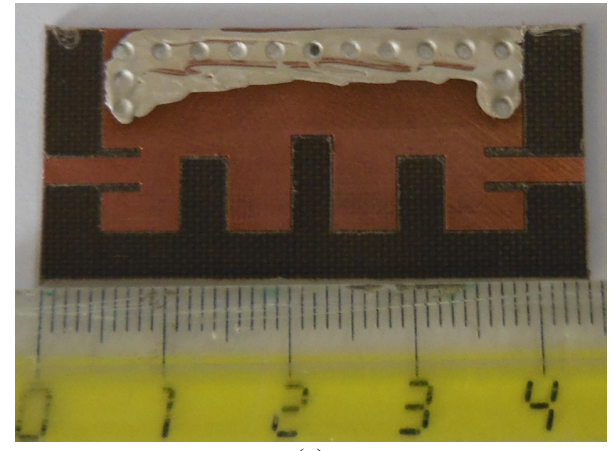

(a)

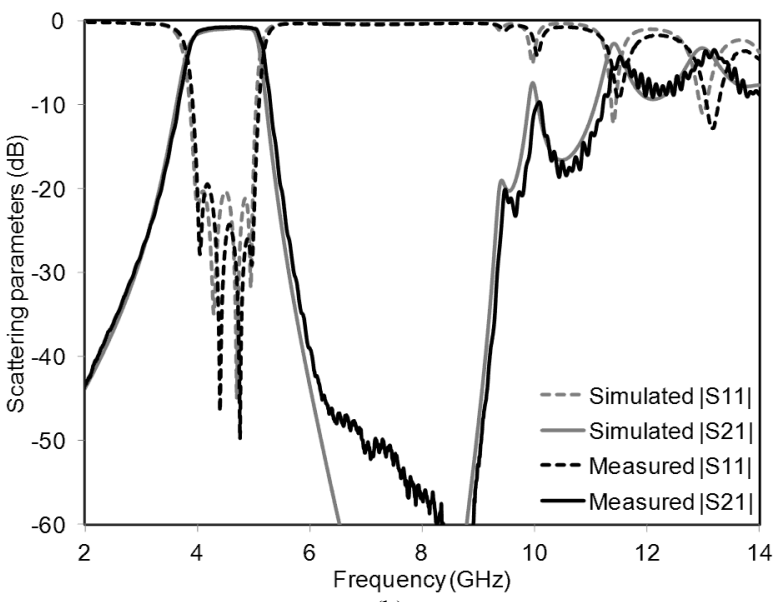

(b)

Fig. 8. Four-pole filter based on a half-mode SIW cavity (from [17]): (a) Photograph of the prototype; (b) Comparison between simulated and measured scattering parameters of the filter.

\subsection{Quarter-Mode SIW Cavity}

The concept of HMSIW cavity can be further extended to obtain a quarter mode SIW cavity (QMSIW). As shown in Fig. 9, a quarter mode-SIW cavity can be obtained by cutting a rectangular SIW cavity into four parts along the symmetry planes [18]. This is obtained by removing the top metal wall and metal vias of three quarters of the cavity, thus reducing the footprint of the cavity by $75 \%$.

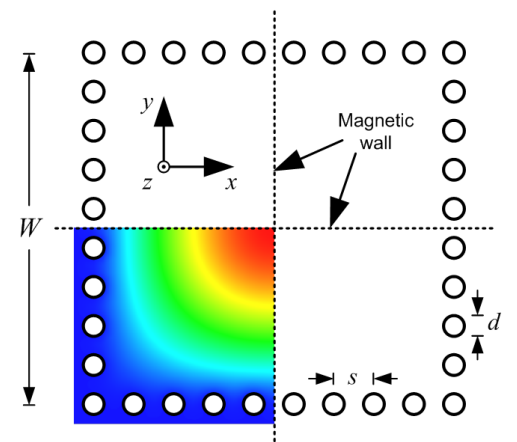

Fig. 9. Geometry of a quarter-mode SIW cavity and representation of the electric field of the fundamental mode (from [18]).

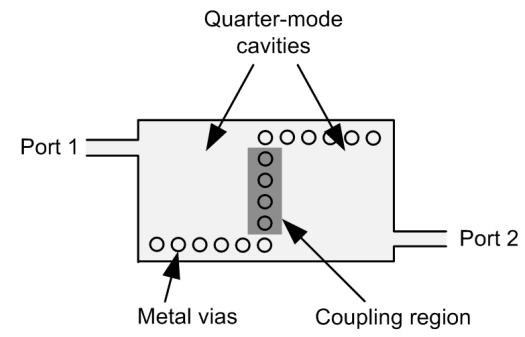

(a)

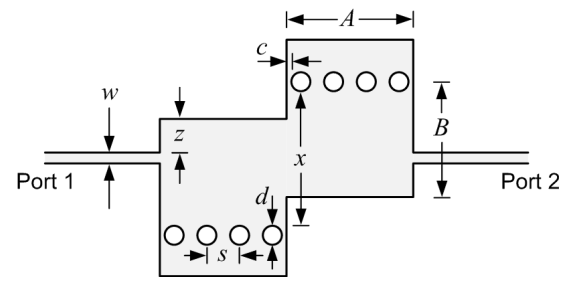

(b)

Fig. 10. Coupling mechanisms in a two-pole filter based on quarter-mode SIW cavity (from [18]): (a) Coupling is obtained by removing the common posts; (b) Coupling is controlled by shifting the two cavities.

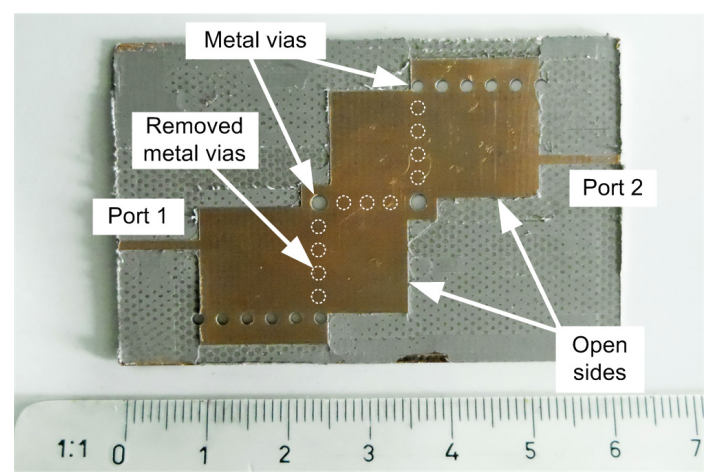

(a)

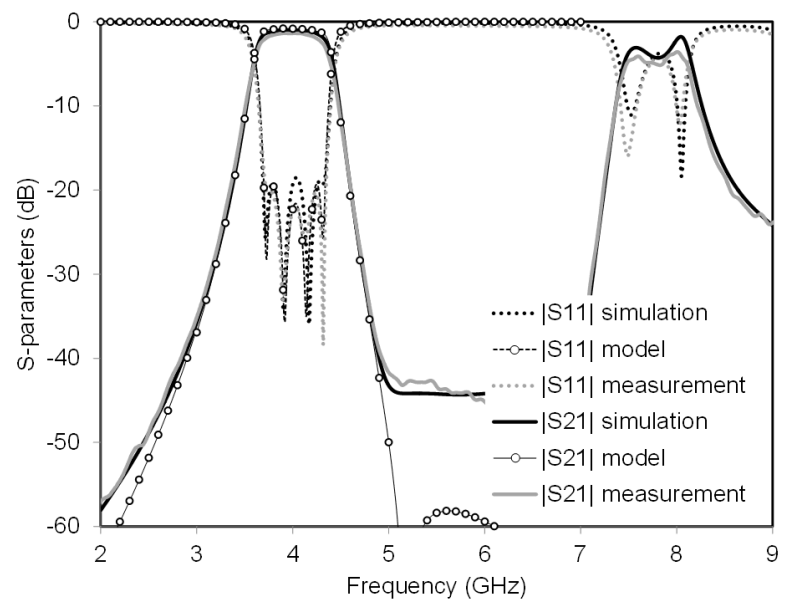

(b)

Fig. 11. Four-pole filter based on a quarter-mode SIW cavity (from [18]): (a) Photograph of the prototype; (b) Comparison between simulated and measured scattering parameters of the filter.

The equivalent circuit of Fig. 4 can be implemented also by using QMSIW cavities. According to Fig. 10a, the coupling between two adjacent QMSIW cavities is obtained by removing the row of common posts. The control 
of the coupling is obtained by side shifting the two cavities, as shown in Fig. 10b. The smaller the shift $x$, the lower is the admittance inverter value. The coupling to input and output transmission lines is instead controlled by the value of $z$ : the larger the shift $z$, the lower is the admittance inverter value. In fact, small values of $z$ mean that the microstrip line is connected to the point where the electric modal field is large (see Fig. 9), thus determining a large external coupling.

A four-pole filter centered at $4 \mathrm{GHz}$ and with an FBW of $16 \%$ has been designed and manufactured in [18]. A dielectric substrate Taconic RF-35, with $\varepsilon_{\mathrm{r}}=3.5$, $\tan \delta=$ 0.0018 , and thickness $t=0.508 \mathrm{~mm}$, was adopted for the fabrication. A photograph of the manufactured prototype is shown in Fig. 11a. Measured results are plotted in Fig. 11b, where also the simulated results and the response of the equivalent circuit are reported.

\section{SIW Based on New Materials}

The use of new materials and fabrication technologies is expected to be a key point of the next generation of wireless systems. The spread of wearable systems will lead to the use of fabric-based components, where the microwave structures are embedded in the garments. Examples of SIW components and antennas in textile have been reported in [19] and [20]. The need to implements eco-sustainable wireless systems is expected to be a strong requirement for some applications, for instance in the field of agriculture and environmental sensing. SIW circuits based on paper substrates and implemented by different techniques have been described in [21]-[23]. Finally, the additive manufacturing represents an emerging area of research, where the microwave components are fabricated by $3 \mathrm{D}$ printing, in a single-pass, low-cost manufacturing process. The fused-deposition modeling has been adopted for the implementation of SIW components and antennas [24], [25], by exploiting the possibility to synthetize the required dielectric material by properly adjusting the infill percentage during the printing.

\subsection{Paper-based SIW Filters}

The use of paper for the implementation of microwave components is particularly interesting, as paper is a cheap material, it is flexible and therefore potentially suitable to the implementation of conformal circuits and antennas, and it is eco-friendly, for those applications (agriculture, environmental monitoring, ...) where reducing the ecological impact is critical.

SIW technology is particularly suitable to the implementation on paper, and two different techniques can be adopted. The use of inkjet printing was proposed in [22]: an inkjet printer, that uses a special ink with silver particles, realizes the top and bottom metal layers of the SIW, and the vias consist of brass rivets. Another approach was adopted in [23]: aluminum foils are pasted at the top and bottom sides of a thick paper sheet by using epoxy glue, to define the top and bottom metallization of the SIW structure; subsequently, a classical milling technique is adopted, and the metal vias are realized by conductive paste. The latter solution avoids the sintering process of the conductive ink and reduces the fabrication to a well establish PCB process.

The filters presented in the previous section and based on classical plastic substrates can be implemented on paper. The filters presented in this section have been fabricated by using the technology described in [23], based on the standard milling processing of a paper layer with aluminum foils. The paper substrate exhibits a thickness of $500 \mu \mathrm{m}$, relative dielectric permittivity $\varepsilon_{\mathrm{r}}=2.2$, and loss tangent $\tan \delta=0.04$.

Two-pole filter on paper, based on a half-mode SIW cavity and operating at the central frequency of $4.5 \mathrm{GHz}$, was proposed in [20]. The photograph of the prototype is shown in Fig. 12a: the filter is quite compact, with a length less than $40 \mathrm{~mm}$, including the input/output microstrip transitions. The simulated and measured frequency response is reported in Fig. 12b, showing a measured insertion loss is $5.0 \mathrm{~dB}$ at the frequency of $4.5 \mathrm{GHz}$.

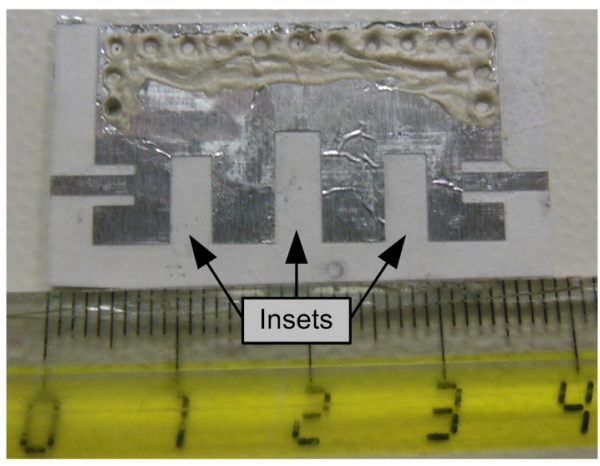

(a)

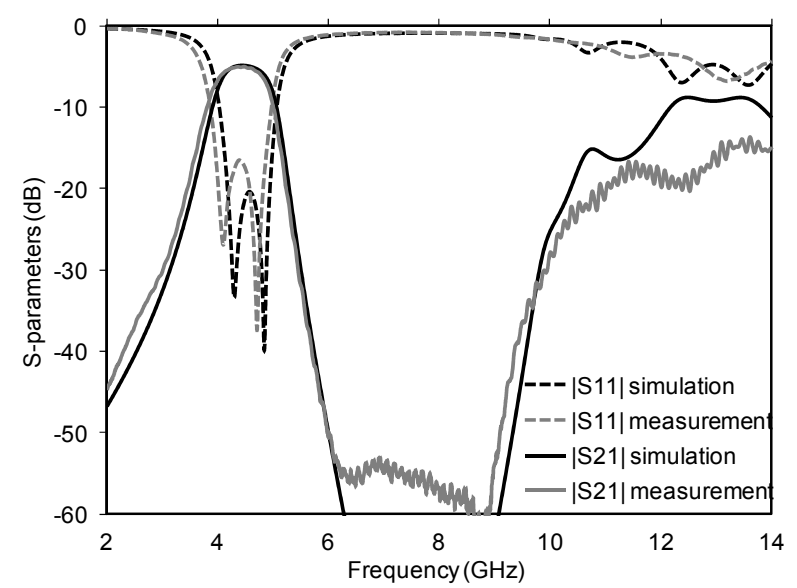

(b)

Fig. 12. Two-pole filter on paper, based on a half-mode SIW cavity (from [26]): (a) Photograph of the prototype; (b) Comparison between simulated and measured scattering parameters of the filter. 


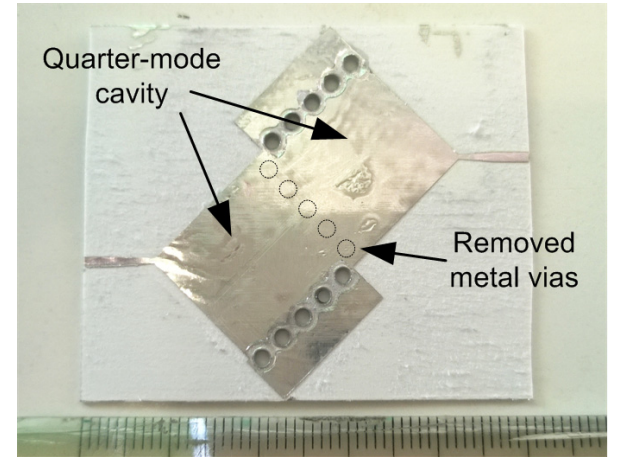

(a)

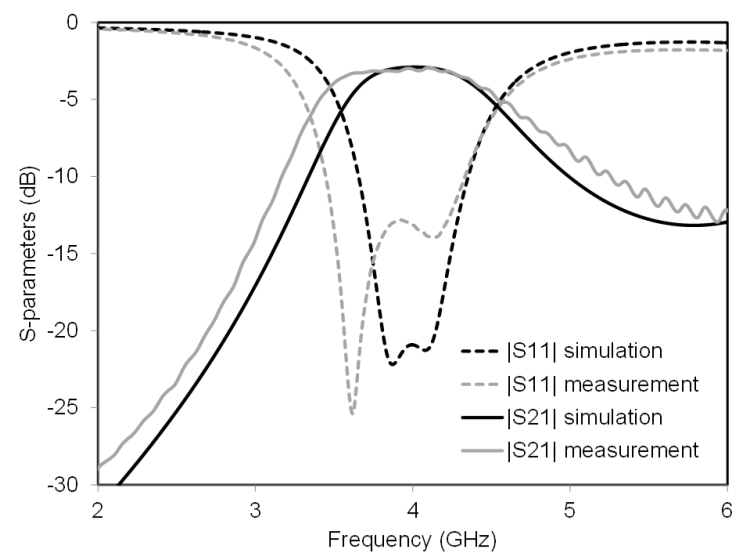

(b)

Fig. 13. Quarter-mode SIW filter on paper, fabricated by milling technique (from [23]): (a) Photograph of the prototype; (b) Comparison between simulated and measured scattering parameters of the filter.

A quarter-mode SIW filter on paper, operating at the frequency of $4 \mathrm{GHz}$, was firstly presented in [23]: it consists of two side-coupled quarter-mode SIW cavities, fed in the corners by microstrip lines with tapered transitions. Fig. 13 shows the photograph of the prototype and the simulated and measured frequency response of the filter.

\subsection{SIW Filters on Textile}

The deployment of wearable electronic devices is gaining increasing popularity, with applications in a variety of different fields, ranging from healthcare to rescue of workers in harsh environments [28]. Among the different solutions for the implementation of wearable devices, the direct use of textile as the substrate for the microwave components and antennas represents a particularly interesting solution, with the results of a perfect integration of the electronics in the garments.

SIW structures have been implemented on textile [19], [20], by using a layer of expanded cell rubber as the dielectric substrate, a conductive fabric (specifically, electro textile) for the metal layers, and brass rivets for the metal vias. Multilayer topologies are possible, by stacking different dielectric layers, with conductive fabric glued in between. The dielectric textile material adopted in this work exhibits a dielectric permittivity $\varepsilon_{\mathrm{r}}=1.575$ and a loss $\operatorname{tangent} \tan \delta=0.0238$, and the single-layer textile with

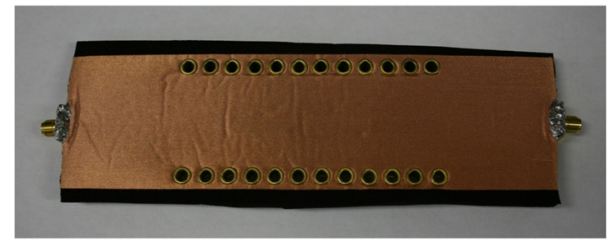

(a)

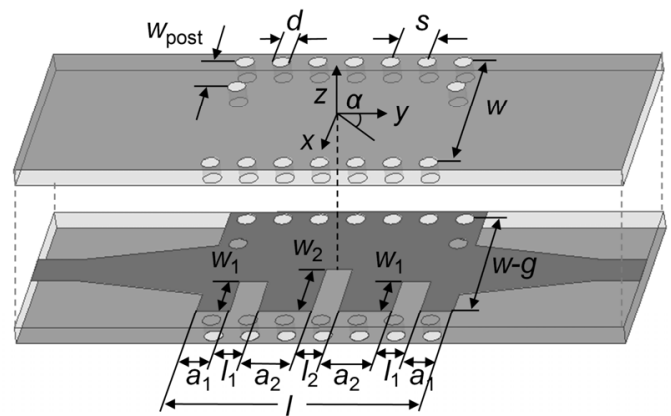

(b)

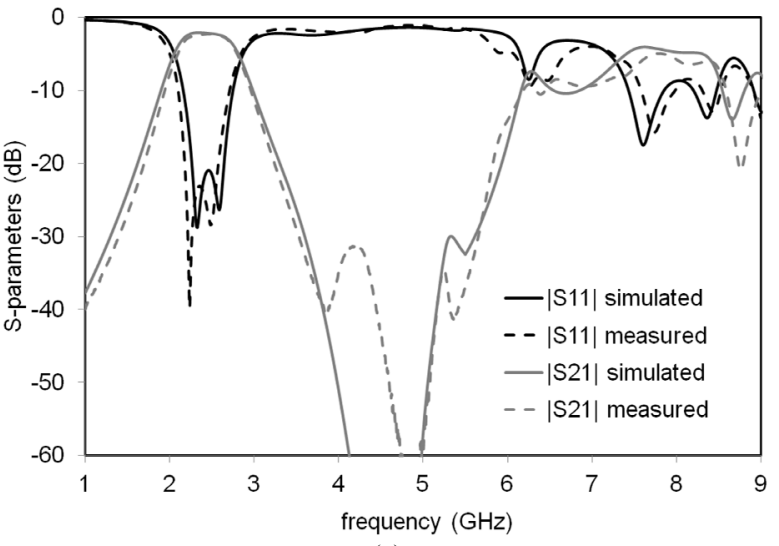

(c)

Fig. 14. Folded SIW filter on textile (from [20]): (a) Photograph of a folded SIW waveguide on textile; (b) Geometry of the filter; (c) Comparison between simulated and measured scattering parameters.

a thickness of $h=3.94 \mathrm{~mm}$. The photograph of a folded SIW structure is shown in Fig. 14a.

A two-pole SIW filter on textile, based on a folded SIW cavity with insets in the middle metal septum, was proposed in [20]. It was designed to operate at the frequency of $2.45 \mathrm{GHz}$, in the industrial, scientific and medical (ISM) band. The geometry of the filter is shown in Fig. 14b, and its simulated and measured frequency response is reported in Fig. 14c. The $3 \mathrm{~dB}$ bandwidth of the filter is $725 \mathrm{MHz}$ and the insertion loss is $2.3 \mathrm{~dB}$ at $2.45 \mathrm{GHz}$.

\subsection{SIW Filters by 3D Printing}

Additive manufacturing techniques are becoming very popular in the microwave community, because they allow a great versatility in terms of shapes, materials, and fabrication process.

SIW structures based on 3D printing has been proposed in last few years, starting from the first 3D wave- 
guide [24] to microfluidic sensors based on a 3D printed SIW cavity [29], and broadband slab SIW structures [25].

Among the variety of 3D printing techniques, the fused deposition modeling (FDM) is particularly interesting, as it allows to print structures with different material density (infill) from $100 \%$ to roughly $10 \%$ [30]. This feature permits to control the dielectric permittivity and loss tangent. In fact, in FDM process, the material is heated and extruded through a nozzle, and deposited to form a twodimensional pattern. Stacked 2D layers results into the final 3D printed structure. One unique feature of the $3 \mathrm{D}$ printing is the capability of changing the density of the printed object, by varying the spacing during the filament deposition.

The flexibility of FDM technique can be conveniently exploited in the design of SIW cavity filters. In [27], ABS filament with dielectric permittivity $\varepsilon_{\mathrm{r}}=2.7$ and loss tangent $\tan \delta=0.02$ was adopted. By using $40 \%$ infill factor, the dielectric permittivity is reduced to $\varepsilon_{\mathrm{r}}=1.6$ and the loss tangent is simultaneously reduced to $\tan \delta=0.008$. The effects are a larger size of the circuit dimensions, as well as an increase in the quality factor of the resonant cavities. Based on this concept, two examples of three-pole

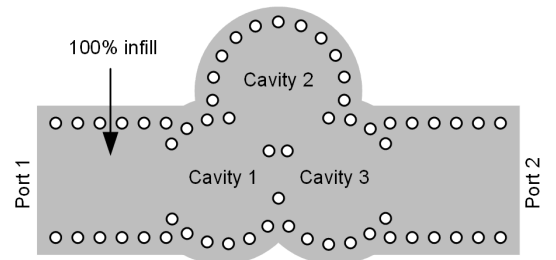

(a)

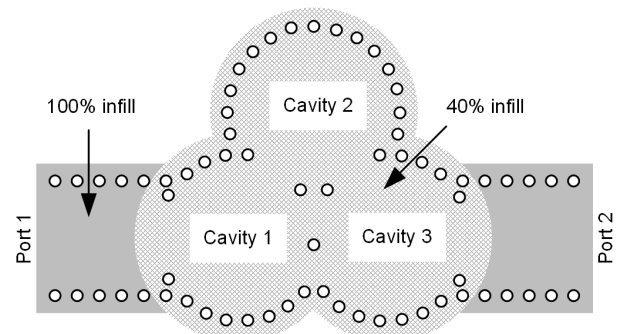

(b)

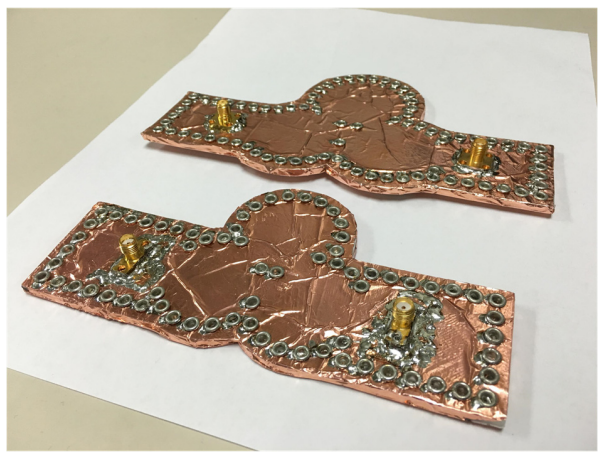

(c)

Fig. 15. 3D printed SIW filter with different infill (from [27]): (a) Geometry of the filter with $100 \%$ infill; (b) Geometry of the filter with $40 \%$ infill; (c) Photograph of the two prototypes. filters were designed in [27]: the former with $100 \%$ infill (Fig. 15a) and the latter with $40 \%$ infill (Fig. 15b). While the smaller infill leads to increased component dimensions (Fig. 15c), it also guarantees an increased Q-factor and lower insertion loss, as demonstrated in [27].

\section{Acknowledgments}

The authors wish to acknowledge Prof. Luca Perregrini and several current and former students at the University of Pavia, Italy, Prof. Manos Tentzeris and his group at the Georgia Institute of Technology, Atlanta, USA, and Prof. Hendrik Rogier and his group at Ghent University, Belgium.

\section{References}

[1] GIUSTO, D., IERA, A., MORABITO, G., ATZORI, L. (Eds.) The Internet of Things. Springer, 2010. DOI: 10.1007/978-1-44191674-7

[2] Special issue: The internet of things. IEEE Wireless Communications, 2010, vol. 17, no. 6. ISSN: 1536-1284

[3] Special issue: The internet of things. IEEE Communications Magazine, 2011, vol. 49, no. 11. ISSN: 0163-6804

[4] RAPPAPORT, T. S., SUN, S., MAYZUS, R., et al. Millimeter wave mobile communications for $5 \mathrm{G}$ cellular: It will work! IEEE Access, 2013, vol. 1, no. 1, p. 335-349. DOI: 10.1109/ACCESS.2013.2260813

[5] BOCCARDI, F., HEATH, R. W., LOZANO, A., MARZETTA, T. L., POPOVSKI, P. Five disruptive technology directions for $5 \mathrm{G}$. IEEE Communications Magazine, 2014, vol. 52, no. 2, p. 74-80. DOI: 10.1109/MCOM.2014.6736746

[6] BOZZI, M., GEORGIADIS, A., WU, K. Review of Substrate Integrated Waveguide (SIW) circuits and antennas. IET Microwaves, Antennas and Propagation, 2011, vol. 5, no. 8, p. 909-920. DOI: 10.1049/iet-map.2010.0463

[7] GARG, R., BAHL, I., BOZZI, M. Microstrip Lines and Slotlines. Artech House, 2013. ISBN: 9781608075355

[8] BASTIOLI, S., TOMASSONI, C., SORRENTINO, R. A new class of waveguide dual-mode filters using TM and nonresonating modes. IEEE Transactions on Microwave Theory and Techniques, 2010, vol. 58, no. 12, p. 3909-3917. DOI: 10.1109/TMTT.2010.2086068

[9] BASTIOLI, S., MARCACCIOLI, L., TOMASSONI, C., SORRENTINO, R. Ultracompact highly-selective dual-mode pseudoelliptic filters. IET Electronics Letters, 2010, vol. 46, no. 2, p. 147-149. DOI: 10.1049/el.2010.2971

[10] BASTIOLI, S., TOMASSONI, C., SORRENTINO, R. TM dualmode pseudoelliptic filters using nonresonating modes. In IEEE MTT-S International Microwave Symposium Digest, p. 880-883. Anaheim (CA, USA), May 2010. DOI: 10.1109/MWSYM.2010.5518108

[11] TOMASSONI, C., BASTIOLI, S., SORRENTINO, R. Generalized TM dual-mode cavity filters. IEEE Transactions on Microwave Theory and Techniques, 2011, vol. 59, no. 12, p. 3338-3346. DOI: 10.1109/TMTT.2011.2172622

[12] TOMASSONI, C., BASTIOLI, S., SNYDER, R. V. Propagating waveguide filters using dielectric resonators. IEEE Transactions 
on Microwave Theory and Techniques, 2015, vol. 63, no. 12, p. 4366-4375. DOI: 10.1109/TMTT.2015.2495284

[13] TOMASSONI, C., BASTIOLI, S., SNYDER, R. V. Compact mixed-mode filter based on $\mathrm{TE}_{101}$ cavity mode and $\mathrm{TE}_{01 \delta}$ dielectric mode. IEEE Transactions on Microwave Theory and Techniques, 2016, vol. 64, no. 12, p. 4434-4443. DOI: 10.1109/TMTT.2016.2623714

[14] GRIGOROPOULOS, N., IZQUIERDO, B. S., YOUNG, P. R. Substrate Integrated Folded Waveguides (SIFW) and filters. IEEE Microwave and Wireless Components Letters, 2005, vol. 15, no. 12, p. 829-831. DOI: 10.1109/LMWC.2005.860027

[15] HONG, W., LIU, B., WANG, Y. Q., et al. Half mode substrate integrated waveguide: A new guided wave structure for microwave and millimeter wave application. In Proceedings of Joint 31st International Conference on Infrared Millimeter Waves and 14th International Conference on Terahertz Electronics. Shanghai (China), Sept. 18-22, 2006, p. $219 . \quad$ DOI: 10.1109/ICIMW.2006.368427

[16] MORO, R., MOSCATO, S., BOZZI, M., PERREGRINI, L. Substrate integrated folded waveguide filter with out-of-band rejection controlled by resonant-mode suppression. IEEE Microwave and Wireless Components Letters, 2015, vol. 25, no. 4, p. 214-216. DOI: 10.1109/LMWC.2015.2400927

[17] DELMONTE, N., SILVESTRI, L., BOZZI, M., PERREGRINI, L. Compact half-mode SIW cavity filters designed by exploiting resonant mode control. International Journal of $R F$ and Microwave Computer-Aided Engineering, 2016, vol. 26, no. 1, p. 72-79. DOI: $10.1002 /$ mmce. 20940

[18] MOSCATO, S., TOMASSONI, C., BOZZI, M., PERREGRINI, L Quarter-mode cavity filters in substrate integrated waveguide technology. IEEE Transactions on Microwave Theory and Techniques, 2016, vol. 64, no. 8, p. 2538-2547. DOI: 10.1109/TMTT.2016.2577690

[19] MORO, R., AGNEESSENS, S., ROGIER, H., BOZZI, M. Wearable textile antenna in substrate integrated waveguide technology. IET Electronics Letters, 2012, vol. 48, no. 16, p. 985-987. DOI: 10.1049/el.2012.2349

[20] MORo, R., AGNEESSENS, S., ROGIER, H., DIERCK, A., BOZZI, M. Textile microwave components in substrate integrated waveguide technology. IEEE Transactions on Microwave Theory and Techniques, 2015, vol. 63, no. 2, p. 422-432. DOI: 10.1109/TMTT.2014.2387272

[21] KIM, S., COOK, B., LE, T., et al. Inkjet-printed antennas, sensors and circuits on paper substrate. IET Microwaves, Antennas and Propagation, 2013, vol. 7, no. 10, p. 858-868. DOI: 10.1049 /ietmap.2012.0685

[22] MORO, R., KIM, S., BOZZI, M., TENTZERIS, M. Inkjet-printed paper-based Substrate Integrated Waveguide (SIW) components and antennas. International Journal of Microwave and Wireless Technologies, 2013, vol. 5, no. 3, p. 197-204. DOI: $10.1017 / \mathrm{S} 1759078713000494$

[23] MOSCATO, S., MORO, R., PASIAN, M., BOZZI, M., PERREGRINI, L. An innovative manufacturing approach for paper-based substrate integrated waveguide components and antennas. IET Microwaves, Antennas and Propagation, 2016, vol. 10, no. 3, p. 256-263. DOI: 10.1049/iet-map.2015.0125

[24] MOSCATO, S., BAHR, R., LE, T., et al. Additive manufacturing of 3D substrate integrated waveguide components. IET Electronics Letters, 2015, vol. 51, no. 18, p. 1426-1428. DOI: $10.1049 / \mathrm{el} .2015 .2298$

[25] MASSONI, E., SILVESTRI, L., ALAIMO, G., et al. 3D-printed substrate integrated slab waveguide for single-mode bandwidth enhancement. IEEE Microwave and Wireless Components Letters, 2017, vol. 27, no. 6, p. 536-538. DOI: 10.1109/LMWC.2017.2701323
[26] MOSCATO, S., DELMONTE, N., SILVESTRI, L., et al. Compact Substrate Integrated Waveguide (SIW) components on paper substrate. In Proceedings of the 45th European Microwave Conference (EuMC 2015), Paris (France), 2015, p. 24-27. DOI: 10.1109/EuMC.2015.7345690

[27] TOMASSONI, C., BAHR, R., TENTZERIS, M., BOZZI, M., et al. 3D printed substrate integrated waveguide filters with locally controlled dielectric permittivity. In Proceedings of the 46th European Microwave Conference (EuMC 2016). London (UK), 2016, p. 253-256. DOI: 10.1109/EuMC.2016.7824326

[28] HeRtLeer, C., ROGIER, H., VAllozzI, L., et al. A textile antenna for off-body communication integrated into protective clothing for firefighters. IEEE Transactions on Antennas and Propagation, 2009, vol. 57, no. 4, p. 919-925. DOI: 10.1109/TAP.2009.2014574

[29] MOSCATO, S., PASIAN, M., BOZZI, M., et al. Exploiting 3D printed substrate for microfluidic SIW sensor. In Proceedings of the 45th European Microwave Conference (EuMC 2015). Paris (France), 2015, p. 28-31. DOI: 10.1109/EuMC.2015.7345691

[30] MOSCATO, S., BAHR, R., LE, T., PASIAN, M., et al. Infill dependent 3D-printed material based on ninjaflex filament for antenna applications. IEEE Antennas and Wireless Propagation Letters, 2016, vol. 15, p. 1506-1509. DOI: 10.1109/LAWP.2016.2516101

\section{About the Authors ...}

Cristiano TOMASSONI was born in Spoleto, Italy. He received the Ph.D. degree in Electronics Engineering from the University of Perugia, Perugia, Italy, 1999. In 1999, he was a Visiting Scientist with the Lehrstuhl für Hochfrequenztechnik, Technical University of Munich, Munich, Germany, where he was involved with the modeling of waveguide structures and devices by using the generalized scattering matrix (GSM) technique. In 2001, he was a Guest Professor with the Fakultät für Elektrotechnik und Informationstechnik, Otto-von-Guericke University, Magdeburg, Germany. During that time, he was involved with the modeling of horn antennas having nonseparable cross sections by using hybrid methods combining three different techniques: the finite-element method (FEM), modematching technique (MMT), and generalized multipole technique (GMT). During his career, he was also involved in the modeling of low-temperature co-fired ceramics (LTCC) by using the method of moments (MoM). Furthermore he studied new analytical methods to implement boundary conditions in the transmission-line matrix (TLM) method and he modeled aperture antennas covered by dielectric radome by using spherical waves. Since 2007, he has been an Assistant Professor with the University of Perugia, where he currently teaches the 'Aerospace Microwave and Radiofrequency Systems' course. His main area of research concerns the modeling and design of waveguide devices and antennas. His research interests also include the development of reduced-size cavity filters, reconfigurable filters, and printed reconfigurable antenna arrays. Cristiano Tomassoni is a member of the MTT-8 Filters and Passive Components Technical Committee. He was the recipient of the 2012 Microwave Prize presented 
by the IEEE Microwave Theory and Technique Society (IEEE MTT-S), recognized to the author of the paper, published in any official IEEE publication during the calendar year, that is judged to be the most significant contribution in the field of interest of the MTT Society.

Maurizio BOZZI was born in Voghera, Italy, in 1971. He received the Ph.D. degree in Electronics and Computer Science from the University of Pavia, Italy in 2000 . He is currently an Associate Professor of the University of Pavia and a Guest Professor of the Tianjin University, China. He held research positions with various universities worldwide, including the Technische Universität Darmstadt, Germany, the Universitat de Valencia, Spain, and the École Polytechnique de Montréal, Canada. He has authored or co-authored more than 100 journal papers and 270 conference papers, and co-authored the book Microstrip Lines and Slotlines (Artech House, 2013). His main research interests concern the development of numerical methods for the electromagnetic modeling and design of microwave and millimeter-wave components with a particular focus on frequency-selective surfaces and substrate integrated waveguides. Prof. Bozzi was the General Chair of the
IEEE MTT-S International Microwave Workshop SeriesAdvanced Materials and Processes (IMWS-AMP 2017), of the IEEE International Conference on Numerical Electromagnetic Modeling and Optimization (NEMO2014), and the General Chair of the IEEE MTT-S International Microwave Workshop Series on Millimeter Wave Integration Technologies (IMWS 2011). Prof. Bozzi is an Elected Member of the Administrative Committee of the IEEE Microwave Theory and Techniques Society (MTT-S) for term 2017-2019. He was the Secretary of IEEE MTT-S for year 2016 and a member of the General Assembly (GA) of the European Microwave Association (EuMA) for the term 2014-2016. Moreover, he is an Associate Editor of the IEEE Microwave and Wireless Components Letters, the IET Microwaves, Antennas and Propagation, and the IET Electronics Letters. He received several awards, including the 2015 Premium Award for the Best Paper in IET Microwaves, Antennas \& Propagation, the 2014 Premium Award for the Best Paper in Electronics Letters, the Best Young Scientist Paper Award of the XXVII General Assembly of URSI in 2002, and the MECSA Prize at the Italian Conference on Electromagnetics (RiNEm) in 2000. 